\title{
ATUAÇÃO DA SOCIEDADE DE DIFUSÃO DO ENSINO DE JAPONESES NO BRASIL NA BAIXADA SANTISTA E VALE DO RIBEIRA.
}

Rafael da Silva e Silval

Resumo: O presente artigo analisa qual foi o impacto da presença da Sociedade de Difusão de Ensino de Japoneses no Brasil na educação na região da Baixada Santista e Vale do Ribeira na primeira metade do século XX. Sabe-se, através da bibliografia sobre o assunto, que a imigração japonesa foi marcada por forte apreço para com a educação. A construção de escolas era uma providência comum para os japoneses uma vez que simbolizava o progresso e a possibilidade de educação das gerações mais novas. Não foi diferente na Baixada Santista e Vale do Ribeira, litoral e região sul do Estado de São Paulo onde pôde-se constatar muitas escolas construídas com o esforço dos próprios colonos japoneses. A partir da década de 1920, o governo do Japão passou a apoiar diretamente a educação nipo-brasileira através do Consulado Japonês, criando para isso a Sociedade de Difusão de Ensino de Japoneses no Brasil. Sendo assim, é possível questionar até a que ponto essa instituição interferiu na atuação de escolas criadas por imigrantes japoneses? Qual foi seu impacto no cotidiano educacional das colônias japonesas nas suas respectivas escolas? Qual era de fato a sua função como instituição vinculada à educação japonesa no Brasil? Para responder tais questões, a pesquisa contou com alguns referenciais de destaque, tais como Tomoo Handa, Arlinda Rocha Nogueira, Zeila de Brito Fabri Demartini, Hiroshi Saito, entre outros. Apoiada na bibliografia, a pesquisa buscou fontes documentais impressas, como fotografias, livros escolares, livros produzidos na época pela colônia etc., e com pesquisa de História Oral realizada desde 2008 com exalunos e pessoas que tiveram alguma relação próxima com colônias japonesas. $\mathrm{O}$ estudo observou que a Sociedade de Difusão do Ensino de Japoneses no Brasil foi fundamental para dar centralidade ao Ensino Japonês, facilitando o envio e qualificação de professores, enviando material didático e proporcionando ajuda financeira às escolas. Por outro lado, a instituição foi alvo direto das ações nacionalistas do estado totalitário de Getúlio Vargas durante o Estado Novo (1937), sendo obrigada a encerrar as suas atividades junto às escolas japonesas.

Palavras-chave: Educação japonesa. Baixada Santista. Vale do Ribeira. História da Educação.

Abstract: The present article is part of a thesis still in progress with prevision to be concluded in the middle of 2016 and intends to analysis the impact of the presence of Japanese Teaching Diffusion Society in Brazil in the education in

Pesquisador na área de História da Educação pelo Centro de Memória da Educação de Praia Grande; professor de História na rede pública de Ensino Fundamental de Praia Grande. Doutorando em Educação pela Universidade Metodista de São Paulo. E-mail: prof.rafae1443556@hotmail.com 
the region of Baixada Santista and Vale do Ribeira on the first half of XX century. It is known, regarding the bibliography about the subject, that the Japanese immigration was recognized for its strong esteem with the education. The construction of schools was a common providence for the Japaneses since it simbolized the progress and the possibility of education for the younger generations. It was not different in Baixada Santista and Vale do Ribeira, seacoast and southern region of São Paulo state where we can find many schools built with the effort of the Japanese settlers. From the decade of 1920 on the government of Japan started supporting directly the Japanese-Brazilian education by the Japanese Consulate, creating for this the Japanese Teaching Diffusion Society in Brazil. Therefore, it is possible to question how far has this institution interfered in the performance of schools created by Japanese immigrants? Which was its impact in the educational everyday of the Japanese colonies at their respective schools? What was its real function as institution linked to the Japanese education in Brazil? To answer the questions above the research made use of some featured references, such as Tomoo Handa, Arlinda Rocha Nogueira, Zeila de Brito Fabri Demartini, Hiroshi Saito, among others. Supported in the bibliography, the research collected printed documental sources as photographs, school books, time books produced by the colony, etc., besides research of Oral History fulfilled since 2008 with former students and people who had some close relation with Japanese colonies. The study observed the Japanese Teaching Diffusion Society in Brazil was crucial to centralize the Japanese Teaching, facilitating both the sending and qualification of teachers, dispatching didactical material and providing financial support to schools. On the other hand the institution was straight target of nationalist actions of Getúlio Vargas' totalitarian state during the New State (1937), being forced to cease its activities towards to Japanese schools.

Key words: Japanese education. Baixada Santista. Vale do Ribeira. History of Education.

\section{INTRODUÇÃO}

No Brasil, a imigração japonesa teve inicio oficialmente em 1908, quando o navio Kasatu Maru atracou no porto de Santos, litoral do Estado de São Paulo, trazendo as primeiras famílias para trabalhar nas fazendas de café (HANDA, 1987). Esse marco foi o início da história da imigração japonesa no Brasil. Em seguida, outras famílias vieram com o sonho de enriquecimento e regresso ao Japão com certa fortuna após alguns anos de trabalho duro nos cafezais. Após décadas de entradas, a emigração japonesa para o Brasil foi interrompida somente durante a Segunda Guerra Mundial, nos anos de governo de Getúlio Vargas, quando o Brasil se posicionou

\footnotetext{
Obra publicada em 1975 pela própria colônia com patrocínio dos comerciantes e produtores locais. Hoje se encontra no acervo do Memorial da Imigração Japonesa (Museu KKKK) e no acervo pessoal do Sr. Eicho Kanashiro, onde a obra foi consultada.
} 
contra o Japão ao lado dos Aliados, adotando uma política de forte nacionalismo (TAKEUSHI, 2002).

Os imigrantes japoneses vieram ao Brasil principalmente para suprir a necessidade de mão de obra nas fazendas de café no interior paulista. Há tempos, os cafezais sofriam com a alta mobilidade dos colonos para outras fazendas ou mesmo para fora delas, buscando outras regiões ou centros urbanos. Os fazendeiros acreditavam que por vir de tão longe, o imigrante japonês teria maior dificuldade para deixar as fazendas em busca de melhores oportunidades (NOGUEIRA, 1973). O Japão, por sua vez, sofria com o aumento da população, a falta de terras cultiváveis e os efeitos da modernização capitalista. Por conta desses problemas, o governo japonês passou a estimular a emigração como forma de aliviar as pressões internas (WAKISAKA, 1971).

Aconteceu, contudo, justamente o contrario do que os cafeicultores esperavam dos imigrantes japoneses. Logo nos primeiros anos, quase a totalidade dos imigrantes deixaram as fazendas para tentar a sorte em outras localidades (NOGUEIRA, 1973). Iniciou-se assim a epopeia das fugas dos japoneses. Arriscando-se na escuridão das noites nas fazendas, em caminhadas sob o sol forte, na possibilidade da recaptura etc.; muitas famílias deixaram as fazendas para formarem núcleos japoneses em várias regiões do Estado de São Paulo e em outros estados do Brasil (HANDA, 1973).

Esse foi o modelo mais comum de entrada e formação de núcleos de imigrantes japoneses no Brasil, contudo, verificou-se também as iniciativas do próprio governo japonês para promover a colonização no Brasil a partir de aquisição e loteamento de terras para famílias cadastradas em companhias de emigração no Japão. A primeira experiência significativa de iniciativa do governo japonês aconteceu no Vale do Ribeira com a atuação da companhia Kaigai Kogyo Kabushiki Kaish, mais conhecida pela sua abreviatura KKKK (VIEIRA, 1973).

O Vale do Ribeira é uma região com cerca de dezesseis mil quilômetros quadrados, compreendida por dezesseis municípios, se estendendo de Peruíbe, ainda no litoral sul da Baixada Santista, no Estado de São Paulo, até o estado do Paraná, com destaque para os municípios de Registro, Iguape e Juquiá; os mais populosos (CARENO, 1997). Sobre a presença japonesa na região, existem registros de 1914 quando imigrantes dessa nacionalidade ingressaram como trabalhadores na construção da linha férrea que ligaria as cidades de Santos e Juquiá. Ao término, muitas famílias permaneceram na região arrendando terras próximas a construção. Segundo Tommo Handa, os pioneiros nas terras arrendadas ao longo da linha Santos-Juquiá sofreram com epidemias de malária e a pouca infraestrutura que a região oferecia, fazendo com que muitos abandonassem as terras posteriormente. A comunidade formada em Praia Grande, por exemplo, foi abandonada após alguns anos de experiência (HANDA, 1987). A partir de Peruíbe, passando por 
Ana Dias, chegando ao município de Itariri e seguindo até a cidade de Miracatu, passando por Pedro de Toledo; apesar das adversidades, muitas famílias conseguiram progredir graças a qualidade do solo, superior ao litoral uma vez que adentra pelo interior e encontra um solo muito mais rico e propicio a uma variedade maior de culturas. Em Itariri e Pedro de Toledo, após tentativas de cultivo de arroz, muitas famílias japoneses progrediram com a cultura da banana, que ganhou importância após a década de quarenta (UECHI, 1975)2. Até os adias atuais, a cultura de banana tem uma forte importância nesses municípios.

Mais adiante, seguindo o Vale do Ribeira sentido o Estado do Paraná, a colônia japonesa ganhou contornos diferenciados devido aos serviços da KKKK. Em 1911, o Governo do Estado de São Paulo elaborou o projeto-lei $\mathrm{n}^{\circ}$ 1299, de 27 de dezembro de 1911, do Patronato Agrícola, determinando a demarcação das terras devolutas com o intuito de firmar os acordos necessários para a devida ocupação de tais terras. Assim, foi firmado um contrato com o Syndicato de Tóquio, sendo este contrato transferido um ano depois para a Companhia Brasil Takushoku Kaish, denominação que foi alterada para Kaigai Kogyo Kabushiki Kaish, a KKKK. O contrato previa a distribuição de terras por parte do Estado de São Paulo à Companhia, que por sua vez ficaria responsável pela efetiva ocupação da região, manter uma boa infraestrutura de estradas de rodagens, garantir a existência de escolas etc. (MIDORIKAWA, 1929). Diferentemente das demais colônias japonesas, onde a maioria das pessoas passava antes pelos cafezais; no Vale do Ribeira, graças aos trabalhos de arrendamento de terras da KKKK, os imigrantes já chegavam com seu lote de terra pré-definido no Japão, sendo que deixavam o porto de Santos direto para lá.

O senhor Eiji Matsumura, por exemplo, relata em seu diário de 1917, encontrado com seu filho Masakaso Matsumura, que foi procurado por agentes de companhias de emigração para deixar o Japão e vir para o Brasil, sendo que do portor de Santos iria direto para a colônia japonesa de Registro. Este diário traz informações muito interessantes sobre o contexto em que os japoneses emigravam para o Brasil. Mostra como ele foi procurado por um agenciador para a emigração. Incerto do que sua aventura lhe traria, também consultava com frequência professores que tinham algum tipo de experiência sobre o assunto para pedir conselho. Ele mesmo foi convidado algumas vezes para ministrar palestras sobre o tema a jovens estudantes. Como era proibido emigrar ao Brasil solteiro, Era comum a formação de famílias compostas, ou seja, casamento arranjado com agregados. Fato presente no documento. Eis o texto do diário:

(dia 24/04) Sr. Nakamura trouxe a notícia de que há candidata para a realização do myai [...]. (dia 30/04) Me acompanharam o Prof. Maruyama, Sr. Nakamura e mais duas pessoas, em comitiva de cinco pessoas, fomos ao local do myai, em Aisome Mura. Eu não sou de acanhar, mas hoje é especial, vou ficar quieto todo 
evento. A moça mostrou aspecto firme o tempo todo, acho que pode enfrentar qualquer situação de dificuldade. Provavelmente por influência da mãe, que demonstrou uma postura educada, mas com rigorosidade.

Sinto correr bem, deixei para o Sr. Nakamura o andamento. A noite após o evento, jantamos no restaurante Hedashima-ya. Retornei do tio. Missão cumprida... Cansei! (MATSUMURA, 1917)

O documento segue relatando a experiência de chegada ao Brasil e a escolha dos lotes oferecidos pela KKKK:

(dia 21/08) Guiado pelo senhor Nomura da Companhia, circulamos para ver o terreno. Estava extremamente cansado por causa da recente recuperação.

As terras são completamente diferentes da expectativa que tinha no Japão e fiquei decepcionado. [...]

(dia 23/08) Solicitei ao Sr. Murakami do Centro de Acomodação de imigrantes para ver a terra nova, mas não há lote que me agrade. (MATSUMURA, 1917)

\section{A EdUCAÇÃo JAPONESA}

Imigração japonesa foi marcada pelo forte apresso a educação. Como regra geral, ao se fundar uma colônia, necessariamente erguia-se junto um local para a Educação, onde também servia como local de discussão de assuntos gerais, reuniões e festas comemorativas (HANDA, 1987). Praticamente em quase todas as colônias japonesas houve algum tipo de escola, das mais rústicas, com paredes de barro e forro de palha, até as mais sofisticadas nos centros urbanos. Ao todo, em 1938, pouco antes da restrição a educação estrangeira imposta durante o Estado Novo, havia cerca de quatrocentas escolas japonesas, entre oficiais e não oficiais (WAKISAKA, 1992).

A origem dessa importância remonta a Revolução Meiji (1968). Durante modernização do país, o governo expandiu o modelo educacional da classe privilegiada dos samurais a toda a sociedade (FAZOLLI FILHO, 1991) como forma de enaltecer a figura do imperador perante o povo e também não deixar a cultura entrar em colapso frente a forte influência ocidental (HOBSBAWM, 2009). Em cerca de trinta anos, noventa e cinco por cento da população japonesa já estava alfabetizada. Assim, aqueles que emigraram para o Brasil, provavelmente trouxeram consigo o espírito de valorização da educação. Além disso, na medida em que os imigrantes se conformavam da impossibilidade de ganhos rápidos, como foi prometido ainda na terra natal e as novas gerações atingiam a idade escolar, surgia a necessidade urgente de se investir na educação das crianças. Havia o temor de que ao regressarem ao Japão, as crianças sofressem preconceito sem saber ler e escrever, além de que os japoneses eram convictos da importância do ensinamento da língua como forma de preservar os ensinamentos dos ancestrais. Por fim, acreditava-se na educação como forma de ascensão social, seja no Brasil ou no Japão (HANDA 1987). 
Dessa maneira, as escolas japonesas rapidamente se multiplicaram pelas colônias do interior e nos centros urbanos. No Vale do Ribeira não poderia ser diferente. Além do esforço coletivo para a fundação de escolas, fazia parte do contrato do Estado com a KKKK a construção e a manutenção de estabelecimentos para a educação (MIDORIKAWA, 1928). Segundo o Álbum de Fotografias de Iguape (1913 - 1934), encontrado no acervo do Memorial da Imigração Japonesa (Museu KKKK), havia na região onze escolas, com destaque para o Grupo Escolar de Registro, o colégio particular Sede da Colônia e a Escola do Campo de Experiência. Havia também locais onde se ensinava a língua japonesa e o português para filhos de imigrantes em instituições religiosas. Em Registro, esse tipo de Educação ficou a cargo da Igreja Católica local e da Igreja Episcopal, cuja sede ficava um pouco mais afastada do centro da cidade de Registro. Um antigo morador local, entrevistado para esta pesquisa por meio de História Oral, afirmou o seguinte sobre essas escolas:

Estudei aqui na escola da Igreja São Francisco Xavier, as professoras eram freiras
e depois, então, eu fui para São Paulo, porque tinha que aprender a língua
japonesa. Aí eu fui lá na Vila São Joaquim, uma escola japonesa que de manhã era
aula de japonês e a tarde aula portuguesa. Taishogaku, a escola, japonesa, não é?
O número da Escola eu não me lembro. Mas foi uma época muito boa, sabe?
(Entrevistado Sr. Augustinho)

Era comum para as crianças japonesas cumprir uma jornada escolar de dois períodos. Em um, estudavam o ensino de japonês, com o material didático e a orientação pedagógica do Japão. No contraturno frequentavam a Educação Brasileira, seguindo a Educação Primária oferecida pelo Estado ou vice e versa. As crianças poderiam cursas as duas orientações educacionais, a brasileira ou a japonesa quando em um mesmo prédio funcionasse as duas modalidades. Isso poderia acontecer quando a escola fosse considerada uma escola particular e arcasse com os gastos dos professores japoneses e brasileiros simultaneamente. Esse foi o caso da Escola Japonesa de Santos, responsável pela centralização da educação japonesa na região da Baixada Santista até o Vale do Ribeira (SILVA E SILVA, 2011). No Vale do Ribeira, nas regiões administradas pela KKKK, em geral, as escolas eram erguidas com esforço da companhia, da comunidade e do Governo Japonês e, em seguida, doadas ao Governo Brasileiro para manter a educação brasileira seguindo o currículo do Estado e no contraturno a comunidade poderia oferecer a educação japonesa com os professores mantidos pela colônia. Após a definição do terreno, doado pela KKKK ou pelos moradores, ergueram-se os prédios e o alojamento dos professores para, em seguida, o Estado manter a Educação Brasileira e a manutenção física necessária. No relatório anual da Delegacia de Ensino de Santos do ano de 1941, o Delegado Prof. Damasco Pena afirma o seguinte sobre as escolas japonesas: 


\begin{abstract}
Examinando-se o mapa escolar da região, logo se destaca um fato importantíssimo: a condenação de escolas na zona de imigração, sem abandono (apezar das inúmeras dificuldades encontradas na sua manutenção) das zonas onde não há imigrantes; e isto fora da estrada de ferro e da rodovia, só ha - dentro da zona de imigração - escolas, onde há núcleos japoneses; veja-se a linha - Vila Batista, são José, Três Barras - veja-se o Bairro do Santo, vejam-se os arredores de Registro e de Sete Barras; e como todas as instalações são ali construídas e cedidas gratuitamente pelos japoneses, chega-se a este outro fato: si não houvesse a boa vontade dos japoneses não haveria a escola estadual. O fato merece ser assinalado, porque denuncia eloquentemente a mentalidade dos imigrantes desta zona, que é fazer escolas estaduais. A isso se deve, principalmente, o êxito dos nossos trabalhos de assimilação (1941).
\end{abstract}

Outras escolas, como foi o caso da escola japonesa do município de Itariri, funcionavam somente com o curso de japonês, em dois períodos, sendo que no contraturno os alunos poderiam frequentar o grupo escolar da região (UECHI, 1975). Mesmo nos quatro tipos de escola apresentados acima, em geral o estudante acabava frequentando as duas orientações distintas, fato este também comum em outras colônias japonesas espalhadas pelo Estado de São Paulo (CARDOSO, 1973).

Nos anos iniciais da imigração japonesa no Brasil, a Educação formal era realizada em casas cedidas por familiares ou professores particulares, com livros trazidos do Japão no momento do embarque para o Brasil. A partir de 1915 surgiram as primeiras escolas, a maioria ainda com parede de barro e forro de palha (HANDA, 1987). O grande salto da educação japonesa aconteceu a partir de 1925 quando o Governo Japonês passou a apoiar com subsídios as instituições nipo-brasileiras de uma maneira geral. Esse fato coincidiu com o fim do subsídio do Governo do Estado de São Paulo para com a imigração japonesa em 1924. A partir desse momento, o Governo Japonês assumiu completamente a subvenção da emigração, uma vez que o Brasil era o único destino disponível no mundo para a emigração japonesa. Além disso, através do Consulado do Japão no Brasil, apoiou diretamente as instituições nipo-brasileiras financeiramente, incentivou a emigração de pessoas com nível superior, principalmente profissionais liberais, como advogados, economista e uma grande quantidade de professores (SAITO, 1961).

\title{
A criação da NihOnjIn KyOIKU FukYu KaI
}

Uma das medidas adotadas pelo Governo Japonês para assegurar o bom funcionamento das instituições nipo-brasileiras, garantindo-lhes subsídios diretos, envio e capacitação de professores e material didático foi a fundação, em 1925, da Zaihaku Nihon-jin Kyoiku-kai (Associação Japonesa de Ensino no Brasil), cuja denominação foi alterada posteriormente para Nihonjin Kyoiku Fukyo-kai (Sociedade de Difusão de Ensino de 
Japoneses do Brasil). Através do Consulado Geral, o governo japonês pretendia capacitar e melhorar o tratamento dos professores, promover seminários e conferências a respeito da educação e aperfeiçoar o material didático. Poderia também direcionar e enviar professores e diretores às escolas necessitadas, abrir outras novas e ajudar financeiramente as existentes e fazer a distribuição do material didático importado do Japão. A entidade possuía filiais instaladas em São Paulo, Santos, Registro, Ribeirão Preto, Presidente Prudente, Promissão, Catanduva, Penápolis, Araçatuba e Ourinhos (WAKISAKA, 1991).

As escolas do Vale do Ribeira estavam vinculadas a cidade de Santos, tratadas como uma única região ao longo da linha férrea Santos-Juquiá. De lá partiam as orientações gerais e o material didático para as escolas do Vale do Ribeira, pois funcionava em Santos, além da Escola Japonesa de Santos, o escritório do Consulado do Japão. Esta escola foi fundada em 1929 com recursos em parte dos associados e outra parte do Consulado Japonês. Oferecia o curso de língua japonesa em um turno e o ensino brasileiro no outro com professores pagos com recursos próprios e ajuda da Sociedade de Difusão de Ensino de Japoneses no Brasil. Possuía quatro turmas de ensino japonês em séries distintas e três turmas de Ensino Primário. Além disso, possuía um alojamento para atender alunos do Litoral Sul e oferecer moradia aos professores e funcionários (SILVA E SILVA, 2011).

Para representar a região do Vale do Ribeira na Sociedade foi indicado Eiji Matsumura em 1937, permanecendo na função até 1941, quando a instituição foi extinta por imposição do Estado Novo. Analisando a documentação presente no acervo pessoal de sua família, principalmente os diários pessoais de 1917 e 1935, pôde-se perceber que Eiji Matsumura foi uma pessoa envolvida com o desenvolvimento coletivo da colônia. Constantemente viajava a Santos e a São Paulo representando os interesses dos produtores locais. Doou o terreno para a construção da Escola do Campo de Experiência recepcionava os professores, tanto japoneses quanto brasileiros que chegavam a região, como consta no diário de 1935. Em julho de 1935, foi nomeado em eleição representante da colônia de Registro. Pelos seus serviços prestados a colônia de Registro, em 1958, foi homenageado pelo Governo Japonês na ocasião dos 50 anos de imigração japonesa para o Brasil pelos serviços prestados a colônia de Registro. (HITOBOTO, 1958).

Em entrevista, seu filho afirma que Matsumura foi nomeado em 1937 para coordenar os serviços da Sociedade de Difusão de Ensino Japonês:

Porque meu pai, veja, aqui em São Paulo funcionava uma entidade financiada pelo Ministério da Educação do Japão, vinha uma certa verba para essa Associação, e a Associação distribuía. O meu pai foi indicado como diretor educacional de Santos. [...] Da entidade! E depois tem o diploma, tudo isso, assinado pelo presidente... Tem o diploma de diretor educacional da Associação de Difusão de Educação Japonesa da regional daqui, da linha Santos-Juquiá, Jipuvura, Registro 
e Sete Barras. [...] Essa entidade era em São Paulo. Dissolveu por causa da Segunda Guerra Mundial. (Entrevistado Sr. Matsumura)

Era o responsável por verificar as remessas de materiais didáticos, cuidar do alojamento dos professores, solicitar docentes etc. Era ele também o responsável por entrar em contato com a Secretaria de Educação para o envio de professores brasileiros. Como consta em seu diário de 1935, no mês de junho, antes mesmo de assumir o cargo, já recepcionava os professores brasileiros enviados de outras regiões. Mesmo assim, a região sempre careceu de professores devido às dificuldades de acessibilidade. Nos relatórios da Delegacia Regional de Ensino de 1936, Damasco Pena alerta para a necessidade de oferecer estímulos aos professores para que atuem nessas regiões e lá permaneçam:

[...] não me importa que me acoimem da primeira concepção do problema educacional - que as escolas se fazem com professor, casa, aparelhamento escolar e meninos. Destes elementos eu só encontrei, reunidos, os meninos. Foi mistér que eu tratasse do resto - das casas, dos professores, do material.

Observando as imagens da família de Matsumura, com frequência participava de reuniões em Santos e em São Paulo. Seu filho relembra que seu pai era muito amigo do professor diretor da Escola de Santos, professor Yanaguisawa. Descobriu-se em pesquisa anterior (2011), que Yanaguisawa foi o diretor responsável pela Escola Japonesa de Santos enviado pela Sociedade com o intuído de coordenar os trabalhos da instituição na região. Assim conta:

Yanaguisawa! Eu conheci muito ele, era da mesma província de meu pai: Nagano [...] Conheci porque meu pai era associado de Nagano, por Nagano tem sua Associação, dos descendentes de Nagano. Yanaguisawa era da mesma província. No tempo de jovem, ele jogava baseball em Santos. (Entrevistado Sr. Matsumura)

Devido às dificuldades apontadas pelos docentes em vários locais de atuação, principalmente quanto ao pagamento de salários, a Sociedade, após uma conferência que reuniu cerca de duzentos professores japoneses, passou a colaborar oferecendo subsídio salarial com recursos do Consulado Geral do Japão. Antes disso, o salário desses professores dependia exclusivamente da contribuição dos colonos locais, deixando-os assim em uma situação delicada. A Autora Zeila de Brito Demartini revela que alguns professores recebiam seus pagaentos em produtos dos colonos, como arroz, animais etc. (DEMARTINI, 2000). Com a atuação da Sociedade, não só o salário dos professores pôde ser melhor ajustado, como a pôde colaborar para melhor formação com a capacitação dos professores através de palestras, seminários e cursos. O próprio professor Yanaguisawa passou por for- 
mação educacional no interior do Estado de São Paulo para então ser indicado para assumir a Escola Japonesa de Santos (SILVA E SILVA, 2011).

Até a metade do século XX a língua japonesa era ensinando basicamente da mesma maneira como no Japão. Nos cadernos escolares encontrados no Museu KKKK, percebeu-se que atividades e exercícios de ensino da língua traziam textos sobre a cultura, os costumes, as lendas, a geografia do país etc. Apesar da intenção de aprimoramento do material didático utilizado nas escolas japonesa, não houve uma preocupação para adequar o conteúdo ao contexto dos filhos dos imigrantes no Brasil até a primeira metade do século XX. No início o material era importado do Japão, sendo produzido posteriormente em São Paulo. Pelo menos na região da Baixada Santista até o Vale do Ribeira foi utilizado o mesmo tipo material, as mesmas cartilhas. Com um caderno encontrado em Santos, apesar de maior escassez de fontes documentais devido a expulsão da colônia em 1945, foi possível encontrar uma cartilha e compara-la com os demais encontrados na cidade de Registro, sete ao todo. Percebeu-se aí a utilização das mesmas orientações didáticas vindas do Consulado Japonês através da Sociedade de Difusão do Ensino de Japonês no Brasil.

Por outro lado, a maioria das escolas japonesas presentes no Vale do Ribeira foi cedida ao governo Brasileiro. Além de ser uma forma encontrada para a manutenção dos prédios e da educação brasileira, vista também com preocupação pelos japoneses frente ao grande número de alunos que frequentavam a educação brasileira. Poderia ser uma forma das autoridades japonesas de não se oporem ao sistema de educação brasileiro. Se por um lado a educação japonesa ainda conservava muitos elementos da educação ministrada no Japão, houve um esforço no sentido de colaboração com o Governo Brasileiro para o bom funcionamento das escolas com as duas orientações educacionais (DEMARTINI, 2006).

\section{NACIONALIZAÇÃO E DIFICULDADES COM A LÍNGUA JAPONESA}

Após a ascensão de Getúlio Vargas ao poder, o país entrou em uma fase de forte nacionalização. Essa política ficou ainda mais evidente com o Estado Novo em 1937 e o forte combate as minorias éticas presentes no país, onde questões ligadas à saúde e a educação passaram ser tratadas como segurança nacional $O$ governo esperava, através da educação, unificar a cultura brasileira pelo espírito de nacionalidade (SKIDMORE, 1987). $\mathrm{O}$ assunto entrou no campo político já na década de trinta quando se percebeu a sua importância para os rumos do país a parti dali (SCHWARTZMAN, 2000).

Inevitavelmente, essas políticas recaíram sobre as colônias japonesas, consideradas perigosas e inassimiláveis (TAKEUCHI, 2002). Indagado sobre as condições das colônias japonesas e sua respectiva educação, o 
delegado regional de ensino Damasco Pena, no relatório de 1941, expressou o seguinte ponto de vista:

\begin{abstract}
O Dr. Almeida Junior teve a bondade de se referir a mim, neste pormenor, declarando que eu soube canalizar para a escola pública a tendência conhecida do japonês em cuidar do ensino. Perdoe Vossa Senhoria que eu aceite a referencia como verdadeira; antevi, desde a chegada á região, em 1932, que o aparelho de ensino particular era precariamente transitório diante da imperiosa necessidade da nacionalização total que, hoje ou amanhã, teria de chegar; e tive a felicidade de poder preparar as coisas para isso. Daí não ter havido qualquer colapso quando foi fechamento das chamadas escolas japonesas, em 1938, semi-japonêsas, porque todas, sem exceção, tinham um professor brasileiro ao lado do japonês e funcionavam na maioria, apropositadamente, dentro dos próprios grupos escolares e das quais eu fui fazendo, pacientemente, meros cursos de língua japonesa e escolas de continuação [...].
\end{abstract}

O Delegado referia-se ao Decreto-lei de 4 de maio de 1938 que visava restringir a entrada de imigrantes e sua atuação no país. Visava por exemplo, no artigo 41, Parágrafo Único que toda e qualquer escola, seja ela particular ou pública, não poderia ser dirigida por estrangeiro. Assim como, segundo o Artigo seguinte, ter denominação em outro idioma. Com isso, o Governo pretendia minar as manifestações estrangeiras, principalmente pelas vias da educação. A situação piorou quando o Brasil entrou na Segunda Guerra Mundial ao lado dos Aliados e se colocou contra o Eixo Alemanha, Itália e Japão. A partir de então, os japoneses passaram a ser vistos não mais como uma questão de nacionalização, mas como problema de segurança nacional. $\mathrm{O}$ fechamento das escolas japonesas passou a ser lembrado negativamente pela colônia, o que pôde ser percebido facilmente nas entrevistas. Eis a fala do Sr. Augustinho:

\footnotetext{
$\mathrm{Na}$ escola japonesa também, quando começou a Guerra, como fechou a escola japonesa, porque fechou aula portuguesa e japonesa, então eu fui em Ipiranga, tinha uma Igreja lá que tinha aula, de manhã era japonês, meio escondido né (risos), e era freira também, e a tarde, aula portuguesa. Então a gente levava o caderno e livro japonês aqui dentro por baixo da blusa, era causa azul, camisa branca e usava palito; então como tinha palito a gente colocava por baixo da camisa e na bolsa aula portuguesa. (Entrevistado Sr. Augustinho)
}

A nacionalização trouxe resultados negativos paras colônias japonesas. Quase todas as escolas do Vale do Ribeira, não só de Registro, apresentaram queda nos índices escolares no relatório do ano de 1943. Essa queda foi consequência direta do fechamento das escolas fundadas por japoneses em todo o Vale do Ribeira. Criou-se, na época, um clima de desconfiança em relação ao ensino japonês. Uma vez proibido, havia o temor que prosseguissem com sua educação de forma clandestina em cursos noturnos. Assim, coloca o Delegado de Ensino Damasco Pena: 
O que posso afirmar é que, depois do dia 20 de dezembro de 1938, ultimo prazo estabelecido pelo Decreto Nacional $n^{\circ} 3010$, nem uma infração foi constatada, a despeito da fiscalização incessante de que são objeto os imigrantes japoneses, por parte de particulares, nacionais e de outras nacionalidades, nem sempre movida - a fiscalização - por questões caracteristicamente escolares. Da zona do Ribeira, onde há conhecidos inimigos da colonização japonesa que fornecem abertamente matéria para comentários de imprensa, nunca depois da citada data, me chegou qualquer denuncia; da zona da estrada de ferro Juquiá, chegam muitas, veiculadas por professores, particulares ou por intermédio dos próprios auxiliares de inspeção, que transmitem, certamente, queixas de particulares [...]

Após o fechamento dos estabelecimentos e a proibição total da educação japonesa, alguns imigrantes ainda tentaram manter seus cursos em escolas clandestinas noturnas, mas que foram deixadas de lado pouco a pouco. Anos mais tarde o ensino da língua japonesa foi retomado, mas em um contexto social e didática educacional diferente do período anterior ao da Segunda Guerra Mundial, quando o Governo Japonês intervia diretamente na educação nipo-brasileira. Quanto às escolas de Registro, o Grupo Escolar foi demolido e no lugar hoje se situa a Prefeitura Municipal. A outra no Campo de Experiência tornou-se definitivamente uma Unidade Estadual com o nome de E. E. Koki Kitajima. A escola de Itariri foi demolida, mas em seu lugar foi construída a Sede da Colônia Japonesa de Itariri. Em Santos, talvez a situação mais dramática, o prédio foi confiscado e permaneceu em poder da União até 2008, quando a Associação Japonesa de Santos conseguiu reaver o prédio. A KKKK teve suas atividades encerradas em 1943 e hoje suas instalações transformaram-se no Museu KKKK. Quanto a Sociedade de Difusão do Ensino Japonês, teve suas atividades encerradas e não mais voltou a funcionar nos anos seguintes.

Algumas CONSIDERAÇÕES

Assim como em outras regiões de colonização japonesa, o Vale do Ribeira conservou a característica de forte apreço à educação devido a presença de pelo menos uma ou mais escolas por município onde houve a presença de colonização dessa nacionalidade. Percebeu-se, pelas instituições investigadas e pelas entrevistas realizadas, determinadas características comuns entre elas, apesar de não seguirem uma padronização rígida de funcionamento. A presença e o direcionamento dos professores, a utilização do material didático e a doação dos prédios ao Governo demonstram condutas administrativas comuns entre as escolas, mesmo estando em municípios distintos. Essas semelhanças entre as escolas provavelmente é resultado da ação da Sociedade de Difusão do Ensino de Japoneses no Brasil. Além disso, a instituição foi fundamental para garantir a presença dos professores japoneses e assegurar a continuidade da educação até a década de quaren- 
ta, uma vez que a região era de difícil acesso, sendo que o Delegado de Ensino colocou nos Relatórios a dificuldade em visitar as regiões e manter professores regularmente o Ensino Primário, solicitando providências para a solução do problema.

Algumas questões, no entanto, permanecem em aberto e necessitam de um aprofundamento posterior. A primeira delas diz respeito à demarcação de terras devolutas realizada pelo Governo a fim de firmar o contrato com a KKKK. É difícil imaginar que toda a extensão das terras cedidas era totalmente desocupada. Assim, chega-se a seguinte questão: Como a população local lidou com a chegada repentina dos imigrantes japoneses e como foi essa relação? Essa primeira questão, atrelada a algumas considerações realizadas no presente texto, leva inevitavelmente a outra questão: Se as escolas construídas pelos imigrantes japoneses foram cedidas ao Governo para funcionarem como escola pública, como foi a relação e a recepção dos filhos das populações locais? Recentemente, encontraram-se pessoas sem ascendência japonesa que estudaram em escolas dessa natureza. Uma delas estudou na escola construída pelos japoneses no bairro de Pedro Barros, no município de Miracatu. Na medida em que se realizar a História Oral e a partir daí produzir novos documentos históricos, será possível fazer novas considerações sobre essas questões e outras que inevitavelmente surgirão.

Ficou evidente que a década de quarenta foi traumática para a colônia e trouxe resultados negativos para a educação japonesa, não só na região estudada, mas em todo o Estado de São Paulo. Resultou em um duro golpe que desarticulou toda uma rede educacional consolidada ao longo da década de trinta pelos trabalhos do Consulado Japonês por meio da Sociedade de Difusão. A proibição da educação japonesa no Brasil prejudicou toda uma geração que vivenciou esse período, que jamais foi a mesma após 1945.

\section{REFERÊNCIAS BIBLIOGRÁFICAS}

ANDO, Zempati; WAKISAKA, Katsunori. Sinopse História da Imigração Japonesa no Brasil. In: CONSUlAdO DO JAPÃO. O Japonês em São Paulo e no Brasil. São Paulo: Consulado Geral do Japão, 1971. p. 4-34.

CARDOSO, Ruth Corrêa Leite. O Papel das Associações Juvenis na Aculturação dos Japoneses. In: SAITO, Hiroshi; MAEYAMA, Takashi. Assimilação e Integração dos Japoneses no Brasil. Petrópolis: Vozes; São Paulo: Universidade de São Paulo, 1973. p. 317-345.

CARENO, Mary Francisca do. Vale do Ribeira: A voz e a vez das Comunidades Negras. São Paulo: Arte \& Ciência/ UNIP, 1997.

DEMARTINI, Zeila de Brito Fabri. Relatos orais de famílias de imigrantes japoneses: Elementos para a história da educação brasileira. Educação \& Sociedade, n. 72, ago, 2000. p. 43-72. 
Relações interétnicas na prática pedagógica. In: ARAUJO, Marta M. (org). Intelectuais, Estado e Educação. Natal: EDUFRN, 2006. p. 163-184.

FAZOLI FILHO, Arnaldo. Educação no Japão. São Paulo: Letras \& Letras, 1991.

HANDA, Tomoo. $O$ imigrante japonês: História da sua vida no Brasil. São Paulo: T.A. Queiroz, 1987.

Vida nas Fazendas de Café. In: SAITO, Hiroshi; MAEYAMA, Takashi. Assimilação e Integração dos Japoneses no Brasil. Petrópolis: Vozes; São Paulo: Universidade de São Paulo, 1973. p. 71-128.

HOBSBAWM, Eric. A Era do Capital (1848 - 1875). São Paulo: Paz e Terra, 2009.

NOGUEIRA, Arlinda Rocha. A imigração japonesa para a lavoura cafeeira paulista (1908 1922). São Paulo: Instituto de Estudos Brasileiros da Universidade de São Paulo. 1973.

SAITO, Hiroshi. O Japonês no Brasil: Estudo de mobilidade e fixação. São Paulo: Fundação Escola de Sociologia e Política de São Paulo, 1961.

SILVA E SILVA. Rafael da. A educação japonesa em Santos (1908 - 1943). 2011. Dissertação (Mestrado em Educação). Universidade Católica de Santos, Santos.

SCHWARTZMAN, Simom; BOMENY, Maria Helena Bousquet; COSTA, Vanda Maria Ribeiro. Tempos de Capanema. São Paulo: Paz e Terra: Fundação Getúlio Vargas, 2000.

SKIDMORE, Thomas. Brasil: de Getúlio Vargas a Castelo Branco, 1930 - 1964. Rio de Janeiro: 8. ed., Paz e Terra, 1982.

TAKEUCHI, Márcia Yumi. O Perigo Amarelo em Tempos de Guerra (1939-1945), São Paulo: Imprensa Oficial do Estado de São Paulo, Arquivo do Estado de São Paulo, 2002.

VIEIRA, Francisca Isabel Schurig. O Japonês na Frente de Expansão Paulista. São Paulo: Pioneira, Ed. da Universidade de São Paulo, 1973.

WAKISAKA, Katsunori (cord.) e outros. Uma epopeia moderna: 80 anos da imigração japonesa no Brasil. São Paulo: Hucitec/Sociedade Brasileira de Cultura Japonesa, 1992.

\section{OUTRAS FONTES CONSULTADAS}

Álbum Colônia de Iguape (1913-1933). Iguape, 1934.

BRASIL. Lei $n^{\circ} 1.299$ de 27 de dezembro de 1911, do Patronato Agrícola.

MATSUMURA, Eiji. Diário pessoal. 1917.

Diário Pessoal. 1935.

HITOBOTO, Kagayakeru. Pessoas brilhantes - livro comemorativo dos 50 anos de Imigração Japonesa no Brasil. Editado pelo Governo Japonês.

MIDORIKAWA, Jorge T. As Colonias Japonezas do Ribeira de Iguape. São Paulo: Secção de Obras do Estado de São Paulo, 1928.

SECRETARIA DE EDUCAÇÃO DO ESTADO DE SÃO PAULO. Relatórios Anual da Delegacia 
Regional do Ensino de Santos. Santos: 1936.

Relatórios Anual da Delegacia Regional do Ensino de Santos. Santos: 1937. Relatórios Anual da Delegacia Regional do Ensino de Santos. Santos: 1939. Relatórios Anual da Delegacia Regional do Ensino de Santos. Santos: 1940. Relatórios Anual da Delegacia Regional do Ensino de Santos. Santos: 1941. Relatórios Anual da Delegacia Regional do Ensino de Santos. Santos: 1943.

UECHI, KOEI. História da Colônia Japonesa de Itariri. Itariri: 1975. 